\title{
Characterization of the Ashbya gossypii secreted N-glycome and genomic insights into its $\mathrm{N}$-glycosylation pathway
}

\author{
Tatiana Q. Aguiar ${ }^{\mathrm{a}}$, Hannu Maaheimo ${ }^{\mathrm{b}}$, Annamari Heiskanen ${ }^{\mathrm{c}}$, Marilyn G. Wiebe ${ }^{\mathrm{b}}$, Merja Penttilä ${ }^{\mathrm{b}}$, \\ Lucília Domingues ${ }^{\mathrm{a}, *}$ \\ a IBB-Institute for Biotechnology and Bioengineering, Centre of Biological Engineering, Universidade do Minho, Campus de Gualtar, 4710-057 Braga, Portugal \\ ${ }^{\mathrm{b}}$ VTT Technical Research Centre of Finland, PO Box 1000, FIN-02044 VTT, Finland \\ ${ }^{\mathrm{c}}$ Glykos Finland Ltd, Helsinki, Finland
}

\section{A R T I C L E I N F O}

\section{Article history:}

Received 8 May 2013

Received in revised form 4 July 2013

Accepted 14 August 2013

Available online 25 August 2013

\section{Keywords:}

Ashbya gossypii

$\mathrm{N}$-Glycan structure

$\mathrm{N}-$ Glycosylation

Secreted glycoproteins

\begin{abstract}
A B S T R A C T
The riboflavin producer Ashbya gossypii is a filamentous hemiascomycete, closely related to the yeast Saccharomyces cerevisiae, that has been used as a model organism to study fungal developmental biology. It has also been explored as a host for the expression of recombinant proteins. However, although $\mathrm{N}$-glycosylation plays important roles in protein secretion, morphogenesis, and the development of multicellular organisms, the N-glycan structures synthesised by A. gossypii had not been elucidated. In this study, we report the first characterization of $A$. gossypii $\mathrm{N}$-glycans and provide valuable insights into their biosynthetic pathway. By combined matrix-assisted laser desorption-ionization time-of-flight (MALDI-TOF) mass spectrometry profiling and nuclear magnetic resonance (NMR) spectroscopy we determined that the A. gossypii secreted N-glycome is characterized by high-mannose type structures in the range $\mathrm{Man}_{4-18} \mathrm{GlcNAc}_{2}$, mostly containing neutral core-type N-glycans with 8-10 mannoses. Cultivation in defined minimal media induced the production of acidic mannosylphosphorylated N-glycans, generally more elongated than the neutral N-glycans. Truncated neutral N-glycan structures similar to those found in other filamentous fungi $\left(\mathrm{Man}_{4-7} \mathrm{GlcNAc}_{2}\right)$ were detected, suggesting the possible existence of trimming activity in A. gossypii. Homologs for all of the S. cerevisiae genes known to be involved in the endoplasmatic reticulum and Golgi $\mathrm{N}$-glycan processing were found in the A. gossypii genome. However, processing of $\mathrm{N}$-glycans by A. gossypii differs considerably from that by S. cerevisiae, allowing much shorter N-glycans. Genes for two putative N-glycan processing enzymes were identified, that did not have homologs in $S$. cerevisiae.
\end{abstract}

(c) 2013 Elsevier Ltd. All rights reserved.

\section{Introduction}

Ashbya gossypii is a pre-whole genome duplication hemiascomycete $^{1}$ that has long been known in the scientific and industrial communities, first as a cotton pathogen and subsequently as a riboflavin overproducer., ${ }^{2,3}$ It grows exclusively in a filamentous way, but has the smallest free living eukaryotic genome known,

Abbreviations: CRM, complex rich medium; DMM, defined minimal medium; DQF-COSY, double quantum filtered correlation spectroscopy; ENGase, endo- $\beta-N$ acetylglucosaminidase; ER, endoplasmic reticulum; F, deoxyhexose; GH85, glycoside hydrolase family 85; GH92, glycoside hydrolase family 92; GlcNAc, $N$-acetylglucosamine; $\mathrm{H}$, hexose; HSQC, heteronuclear single quantum coherence; MALDI-TOF, matrix-assisted laser desorption-ionization time-of-flight; Man, mannose; $\mathrm{m} / \mathrm{z}$, mass-to-charge ratio; $\mathrm{N}, \mathrm{N}$-acetylhexosamine; NAc, $\mathrm{N}$-acetyl; NMR, nuclear magnetic resonance; NOESY, nuclear Overhauser enhancement spectroscopy; $P$, phosphate; PNGase F, peptide:N-glycosidase F; TOCSY, total correlation spectroscopy; vvm, volumes of air per volume of liquid per minute; $1 \mathrm{D}$, one-dimensional; $2 \mathrm{D}$, twodimensional.

* Corresponding author. Tel.: +351 253604 400; fax: +351 253604429 .

E-mail address: luciliad@deb.uminho.pt (L. Domingues). which shares a high degree of gene homology and gene order conservation with that of Saccharomyces cerevisiae. ${ }^{1}$

The similarities of $A$. gossypii to both yeast and filamentous fungi, its small genome, haploid nuclei, and ease of genetic manipulation led to expanded interest in this organism beyond riboflavin production. Over the past two decades A. gossypi has been used as a model organism to study the biological processes and regulatory mechanisms that govern the differences between filamentous and yeast growth. ${ }^{3,4}$ Recently, it has also been considered as a host for the expression of recombinant proteins. ${ }^{5}$

Sustained polarized hyphal growth and generally high secretion capacity are typical features of filamentous fungi that distinguish them from yeast. Interestingly, although its secretory pathway remains poorly characterized, there is evidence that the level of protein secretion in A. gossypii is more similar to that of yeast than to that of other filamentous fungi. ${ }^{5}$

In eukaryotes, proteins destined for the secretory pathway are targeted to the endoplasmatic reticulum (ER), where they are folded and can undergo post-translational modifications. They 
are then transferred to the Golgi apparatus, where they undergo further processing before being delivered to the plasma membrane for exocytosis by vesicles of the distal secretory system. ${ }^{6,7}$ In filamentous fungi this is a highly polarized process, which takes place mainly at hyphal tips through intricate mechanisms as yet not fully understood. ${ }^{6-8}$ Recently, the importance of protein glycosylation in the polarized biosynthetic sorting of proteins and filamentous growth has become increasingly evident. ${ }^{9-12}$

Glycosylation is a post-translational modification that strongly influences protein folding, secretion, cellular localization, and biological activity. ${ }^{13}$ It involves the covalent attachment of one or more carbohydrates (glycans) to a protein, providing a means to enhance its structural and functional diversity. In most cases, the attachment is to an asparagine residue (within the sequence Asn-X-Ser/Thr, where X denotes any aminoacid except proline) in a process termed $\mathrm{N}$-glycosylation. The early stages of N-glycan processing within the ER are highly conserved among eukaryotes, whereas the further trimming and elongation of the core structures made in the ER differ remarkably between species and even between individual proteins within a single species or cell type. ${ }^{14}$

$\mathrm{N}-$ Glycosylation has been well studied in several biotechnologically important yeast and filamentous fungi, mostly in those with potential as recombinant protein producers, as the type of sugars that compose the N-glycans, along with the extent and structure of these polymers greatly affects the production, stability, and bioactivity of recombinant glycoproteins. ${ }^{15,16}$ Fungal N-glycans are mainly composed of mannosyl residues (high-mannose type), although additional residues, such as $\mathrm{N}$-acetylglucosamine, glucose, galactose, xylose, fucose, pyruvate, or phosphate may also be found in some species. ${ }^{15,17-20}$ Yeast often specialize their high-mannose $\mathrm{N}$-glycans further by extending them into large hypermannosylated outer chains. ${ }^{17}$ In contrast, although there are reports pointing to the occurrence of hypermannosylated $\mathrm{N}$ glycans in specific strains, filamentous fungi most often synthesize small high-mannose type N-glycans. ${ }^{15,18}$ Although no information is available on the composition and structural characteristics of $A$. gossypii $\mathrm{N}$-glycans, Ribeiro et al. ${ }^{5}$ suggested that they may be less extensively glycosylated than $S$. cerevisiae glycans.

The mannosyltransferase Och1 protein is the key enzyme for the synthesis of hypermannosylated outer chains in yeast and filamentous fungi. Recent findings suggest a link between filamentous growth and Och1 proteins having a signal peptide. ${ }^{10}$ Of particular interest is the putative Och1 protein of A. gossypii that, although being highly homologous to its $S$. cerevisiae counterpart, was predicted to have an $\mathrm{N}$-terminal signal sequence like that found in other filamentous fungi rather than an N-terminal membrane anchor, as predicted for yeast Och1 proteins. ${ }^{10}$

Considering the unique characteristics of $A$. gossypii and that, to our knowledge, no information was available on the N-glycan structures synthesized by this fungus, we undertook a global analysis of the N-glycans attached to its secreted glycoproteins by matrix-assisted laser desorption-ionization time-of-flight (MALDI-TOF) mass spectrometric profiling and nuclear magnetic resonance (NMR) spectroscopy. Here, we report the first characterization of $A$. gossypii $\mathrm{N}$-glycan structures, including culture medium- and cultivation stage-specific $\mathrm{N}$-glycan profiles, to provide an enriched context for assessing overall $\mathrm{N}$-glycosylation heterogeneity in A. gossypii.

\section{Materials and methods}

\subsection{Strain, media, and culture conditions}

The strain used in this study was A. gossypii ATCC 10895, kindly provided by Prof. P. Philippsen (Biozentrum, University of Basel,
Switzerland). Stock cultures were maintained as spores suspended in $20 \%(\mathrm{v} / \mathrm{v})$ glycerol, $0.8 \%(\mathrm{w} / \mathrm{v}) \mathrm{NaCl}$ with $0.025 \%(\mathrm{v} / \mathrm{v})$ Tween 20 at $-80^{\circ} \mathrm{C}$. For bioreactor inoculation, $50 \mathrm{~mL}$ pre-cultures, inoculated with $10^{6}$ spores, were cultivated in $250 \mathrm{~mL}$ Erlenmeyer flasks at $30^{\circ} \mathrm{C}$ and $200 \mathrm{rpm}$. Pre-cultures were grown in Ashbya Full Medium $^{21}$ for $17 \mathrm{~h}$ before being harvested by filtration through disks of sterile disposable cleaning cloth (X-tra, Inex Partners Oy, Finland) and resuspended in an appropriate volume of sterile distilled water. Bioreactors were inoculated to an initial biomass of $0.55 \mathrm{~g} / \mathrm{L}$. Batch cultivations were carried out in B. Braun Biotech International (Sartorius AG, Germany) Biostat ${ }^{\circledR}$ B-DCU (2.0 L working volume) bioreactors containing $1.2 \mathrm{~L}$ of either defined minimal medium (DMM) ${ }^{22}$ or complex rich medium (CRM; $1 \%(w / v)$ tryptone, $1 \%(\mathrm{w} / \mathrm{v})$ yeast extract, $0.1 \%(\mathrm{w} / \mathrm{v})$ myo-inositol), both with $2 \%(\mathrm{w} / \mathrm{v})$ sucrose as carbon source. Polypropylene glycol (mixed molecular weights ${ }^{23}$ ) was added to a final concentration of $0.2 \%$ (v/v) to control foam production. Cultures were grown at $30^{\circ} \mathrm{C}$, with $600 \mathrm{rpm}$ agitation and aeration of 2.4 volumes of air per volume of liquid per minute (vvm). Culture $\mathrm{pH}$ was maintained at $6.0 \pm 0.1$ by the addition of sterile $1 \mathrm{M} \mathrm{KOH}$ or $1 \mathrm{M} \mathrm{H}_{3} \mathrm{PO}_{4}$. A. gossypii maximum specific growth rate in DMM was $0.22 \pm 0.01 \mathrm{~h}^{-1}$ and in CRM $0.36 \pm 0.01 \mathrm{~h}^{-1}$. Culture supernatants were collected by filtration and stored at $-20^{\circ} \mathrm{C}$ until further use. For dry weight determination, mycelia were harvested from $5 \mathrm{~mL}$ of fermentation broth by filtration through disks of disposable cleaning cloth (Xtra), washed with 2 sample volumes of distilled water and dried to a constant weight at $100^{\circ} \mathrm{C}$. Triplicate samples were taken for all biomass measurements.

\subsection{Preparation of N-glycans for MALDI-TOF mass spectrometry}

The protein content of the culture supernatants collected during exponential (Biomass: $1.9 \mathrm{~g} / \mathrm{L}$ for DMM and $2.9 \mathrm{~g} / \mathrm{L}$ for CRM), early stationary (Biomass: $5.5 \mathrm{~g} / \mathrm{L}$ for DMM and 7.6 g/L for CRM) and late stationary (Biomass: $5.7 \mathrm{~g} / \mathrm{L}$ for DMM and $8.1 \mathrm{~g} / \mathrm{L}$ for CRM) phases was determined by the Bradford protein assay (Bio-Rad, USA) and $500 \mu \mathrm{L}$ of each sample (5-45 $\mu \mathrm{g}$ of total protein) was taken for mass spectrometry N-glycan profiling. Samples of the culture media alone were also analyzed. N-Glycans were detached from the secreted glycoproteins by Flavobacterium meningosepticum peptide: N-glycosidase F (PNGase F; Prozyme, USA) digestion and purified by organic extraction-precipitation and miniaturized solid-phase extraction steps as described by Hemmoranta et al. ${ }^{24}$

\subsection{Mass spectrometry}

MALDI-TOF mass spectrometry was performed on a Bruker Ultraflex III TOF/TOF instrument (Bruker Daltonics, Germany) as previously described. ${ }^{24}$ Neutral N-glycans were detected in positive ion reflector mode as $[\mathrm{M}+\mathrm{Na}]^{+}$ions and acidic $\mathrm{N}$-glycans were detected in negative ion reflector mode as $[\mathrm{M}-\mathrm{H}]^{-}$ions. The software FlexAnalysis 3.3 (Bruker Daltonics, Germany) was used for analysis of the mass spectra. Relative molar abundances of neutral and acidic glycan components were assigned based on their relative signal intensities in the mass spectra when analyzed separately as the neutral and acidic N-glycan fractions. The presented glycan profiles were extracted from the resulting signal lists by removing the effect of isotopic pattern overlapping, multiple alkali metal adduct signals, products of elimination of water from the reducing oligosaccharides, and other interfering mass spectrometric signals not arising from the original glycans in the sample. The resulting glycan signals in the presented glycan profiles were normalized to $100 \%$ to allow comparison between samples. ${ }^{24}$ 


\subsection{Preparation of $\mathbf{N}$-glycans for NMR analysis}

Approximately $750 \mathrm{~mL}$ of DMM culture supernatant was collected during late stationary phase by filtration and concentrated under vacuum in a RapidVap ${ }^{\circledR} \mathrm{N} 2 / 48$ Evaporation System (Labconco Corporation, USA) to a final volume of $40 \mathrm{~mL}$. Subsequently, the proteins were precipitated overnight at $-20^{\circ} \mathrm{C}$ with 2 volumes of ice-cold acetone containing $10 \%(\mathrm{v} / \mathrm{v})$ trichloroacetic acid. The pellet was washed twice with ice-cold acetone, dried at room temperature and redissolved with $8 \mathrm{~mL}$ of $20 \mathrm{mM}$ sodium phosphate buffer, $\mathrm{pH}$ 7.3. Proteins $(100 \mathrm{mg}$ ) were denaturated in $50 \mathrm{~mL}$ polypropylene tubes by heating at $100{ }^{\circ} \mathrm{C}$ for $5 \mathrm{~min}$ in the presence of $0.1 \%(\mathrm{w} / \mathrm{v})$ sodium dodecyl sulfate and $1 \%(\mathrm{v} / \mathrm{v}) 2$-mercaptoethanol. After addition of $0.75 \%(\mathrm{v} / \mathrm{v})$ Nonidet P-40 and $2 \mathrm{U} / \mathrm{mL}$ of PNGase F (Roche, Germany), N-glycans were released from the glycoproteins by digestion at $37^{\circ} \mathrm{C}$ for $48 \mathrm{~h}$. Glycans were extracted by selective organic procedures essentially as previously described. ${ }^{25}$ Briefly, proteins and glycans were precipitated with 4 volumes of ice-cold acetone at $-20^{\circ} \mathrm{C}$ and the glycans extracted twice from the pellets with $60 \%(\mathrm{v} / \mathrm{v})$ ice-cold methanol at $-20^{\circ} \mathrm{C}$. The two extracts were combined and dried. Prior to NMR experiments, the isolated glycans were lyophilized twice from $99.8 \%$ methanol- $d_{4}$ (MeOD; Sigma-Aldrich), repeatedly exchanged with $99.9 \%$ deuterium oxide $\left({ }^{2} \mathrm{H}_{2} \mathrm{O}\right.$; Sigma-Aldrich), with intermediate lyophilization, and finally dissolved in $600 \mu \mathrm{L}^{2} \mathrm{H}_{2} \mathrm{O}$.

\subsection{NMR spectroscopy}

The ${ }^{1} \mathrm{H}$ NMR spectra were recorded at $10^{\circ} \mathrm{C}$ or $25^{\circ} \mathrm{C}$ on a $600 \mathrm{MHz}$ Bruker Avance III NMR spectrometer equipped with a QCI Cryoprobe. One-dimensional (1D) ${ }^{1} \mathrm{H}$ spectra were recorded with $4 \mathrm{~s}$ presaturation of the residual water signal using the $1 \mathrm{D}$ NOESY presaturation sequence. Two-dimensional (2D) DQF-COSY and TOCSY spectra were recorded using standard Bruker pulse sequences. In TOCSY, the mixing time used was $80 \mathrm{~ms}$. The ${ }^{31} \mathrm{P}$ decoupled ${ }^{1} \mathrm{H}$ spectrum was recorded with GARP4 ${ }^{31} \mathrm{P}$ decoupling ${ }^{26}$ during the acquisition time. The ${ }^{1} \mathrm{H}^{31} \mathrm{P}$ HSQC spectrum was recorded with standard echo/antiecho-TPPI gradient selection pulse sequence and GARP4 ${ }^{31} \mathrm{P}$ decoupling ${ }^{26}$ during the acquisition time. The ${ }^{1} \mathrm{H}^{31} \mathrm{P}$ coupling constant was estimated to $8 \mathrm{~Hz}$. The ${ }^{1} \mathrm{H}$ chemical shifts were referenced to internal acetone $\left(\delta 2.225\right.$ in $\left.{ }^{2} \mathrm{H}_{2} \mathrm{O}\right)$ and the ${ }^{31} \mathrm{P}$ chemical shifts were referenced to external $85 \%$ phosphoric acid (0 ppm).

\subsection{In silico analysis of the $A$. gossypii N-glycosylation pathway}

The Ashbya Genome Database (http://agd.vital-it.ch) ${ }^{27}$ was used to map a set of $S$. cerevisiae genes involved in the various steps of the N-glycosylation pathway to A. gossypii genes (Table 1 ). To search for putative $A$. gossypii genes encoding glycoside hydrolases and glycosyltransferases, with a possible role in N-glycosylation and for which the homolog was absent in S. cerevisiae, the Carbohydrate-Active enZYmes (CAZy) database (www.cazy.org) e189.html) ${ }^{28}$ was used. Prediction of signal peptides or signal anchors on putative proteins was done using SignalP 3.0 (www.cbs.dtu.dk/services/SignalP-3.0/) and MultiLoc2-HighRes (Fungal) (http://www-bs.informatik.uni-tuebingen.de/Services/ MultiLoc2) was used to predict subcellular protein localization.

\section{Results}

\subsection{A. gossypii neutral N-glycan profiles}

Neutral and acidic N-glycans derived from A. gossypii secreted proteins were analyzed separately by MALDI-TOF mass spectrometry. Using a mass matching approach, monosaccharide composi- tions were proposed for different glycan signals and annotated in the mass spectra profiles (Figs. 1 and 2).

In the positive-ion mode mass spectra of the neutral $\mathrm{N}$-glycans (Fig. 1), a series of peaks predominated with mass-to-charge ratio $(\mathrm{m} / \mathrm{z})$ values that correlated with the $[\mathrm{M}+\mathrm{Na}]^{+}$adduct ions of highmannose type $\mathrm{N}$-glycans ranging in size from H4N2 to H18N2. The high-mannose type N-glycans with composition H8N2, H9N2, and $\mathrm{H} 10 \mathrm{~N} 2$ were enriched in all of the neutral N-glycan pools, and only minor relative amounts of $\mathrm{N}$-glycans containing more than 11 hexoses were detected. N-Glycans containing 7 hexoses (H7N2) were also enriched in the neutral $\mathrm{N}$-glycan pools during exponential growth in complex rich medium (Fig. 1B), decreasing during stationary phase (Fig. 1D and F). In agreement with these results, chemical shifts typical of a mixture of high-mannose type N-glycan structures with an average of nine mannoses per molecule were observed by ${ }^{1} \mathrm{H}$ NMR spectroscopy of the total pool of unfractionated N-glycans (Fig. 3, Table 2).

As is evident from Figure 1, the size distribution and relative amounts of neutral N-glycans were generally similar during cultivation in both defined minimal and complex rich medium, although a higher amount of small (H4N2 to H7N2) and high (H16N2 to H18N2) molecular weight glycan structures was observed when complex medium was used. In minimal medium, three pseudomolar ion signals observed at $m / z$ 1241.3, 1386.3, and 1531.2 were among the most abundant signals observed during exponential growth (Fig. 1A). Of these, only the signal at $\mathrm{m} / \mathrm{z}$ 1241.3 corresponded to the molecular weight of a known N-glycan, with the monosaccharide composition H4N2F1. However, no evidence was obtained from our NMR data for the presence of fucosylated $\mathrm{N}$-glycans in A. gossypii (see Section 3.3), nor were genes putatively encoding for fucosyltransferases found in the A. gossypii genome. The molecular weight of the peak at $m / z 1531.2$ correlated with a series of ion signals that were observed later in the cultivations at $162 \mathrm{~m} / \mathrm{z}$ intervals (indicated with arrows in Fig. 1), which is the molecular weight of a hexose. Considering that these signals did not correspond to known $\mathrm{N}$-glycans nor to contaminants from the media, they are referred to here as unknown polyhexose contaminants.

\subsection{A. gossypii acidic $\mathrm{N}$-glycan profiles}

Acidic N-glycans were only detected when A. gossypii was grown in a defined minimal medium (Fig. 2), as all ion signals observed in the negative ion mode mass spectra from cultivation in complex rich medium corresponded to known contaminants from the culture medium (not shown).

In minimal medium, a series of peaks predominated in the acidic $\mathrm{N}$-glycan profiles (Fig. 2) at $\mathrm{m} / \mathrm{z}$ values that correlated with the $[\mathrm{M}-\mathrm{H}]^{-}$adduct ions of monophosphorylated/monosulfated high-mannose type $\mathrm{N}$-glycans ranging in size from P1H5N2 to $P 1$ 171N2. Consistent with these results, NMR spectroscopy revealed the presence of mannosylphosporylated N-glycans, but no evidence for the presence of sulfate (see Section 3.3).

N-Glycans with composition P1H5N2, P1H13N2, P1H14N2, and $P 1 H 15 N 2$ were enriched in the acidic N-glycan pools during the stationary phase, while $P 1 \mathrm{H} 5 \mathrm{~N} 2$ was also enriched during exponential growth. In general, the major acidic $\mathrm{N}$-glycan structures present during the stationary phase were about five hexose units larger than the major neutral N-glycans.

Similar to what was observed in the neutral N-glycan profiles, the negative ion mode mass spectra from cultivation in defined minimal medium also included a series of peaks at $160 \mathrm{~m} / \mathrm{z}$ intervals ( $m / z$ values indicated with boxes in Fig. 2 ), that did not correspond to known contaminant signals from the media, and which were among the major signals detected during the exponential growth. The $m / z$ values of these peaks correlated with the $[\mathrm{M}-\mathrm{H}]^{-}$ 
Table 1

Putative A. gossypii genes predicted to be involved in the N-glycan biosynthetic pathway

\begin{tabular}{|c|c|c|}
\hline Predicted protein function & S. cerevisiae gene & A. gossypii gene \\
\hline \multicolumn{3}{|l|}{ Synthesis and transport of sugar nucleotide donors } \\
\hline Glutamine-fructose-6-phosphate amidotransferase & GFA1, YMR084W, YMR085W & ABL036C \\
\hline Glucosamine-6-phosphate $N$-acetyltransferase & GNA1 & AFR510W \\
\hline $\mathrm{N}$-Acetylglucosamine-phosphate mutase & PCM1 & ACR015W \\
\hline UDP-N-acetylglucosamine pyrophosphorylase & QRI1/UAP1 & AFL192C \\
\hline \multicolumn{3}{|l|}{ GDP-Man } \\
\hline Mannose-6-phosphate isomerase & PMI40 & ADR003C \\
\hline Phosphomannomutase & SEC53 & $A B R 236 W$ \\
\hline Phosphoglucomutase & PGM1, PGM2 & ABL029W \\
\hline Phosphoglucomutase & PGM3 & $A B L 126 W$ \\
\hline Mannose-1-phosphate guanyltransferase & PSA1/MPG1 & AFR599W \\
\hline Guanosine diphosphatase & GDA1 & AFR362C \\
\hline Apyrase with wide substrate specificity & YND1 & ADR006W \\
\hline GDP-mannose transporter & VRG4, HVG1, YER039C-A & AFR236C \\
\hline Putative nucleotide sugar transporter similar to $\operatorname{Vrg} 4 \mathrm{p}$ & YMD8 & AFR462C \\
\hline \multicolumn{3}{|l|}{ UDP-Glc } \\
\hline Glucokinase & GLK1, EMI2 & AFR716C \\
\hline Hexokinase & HXK1, HXK2 & AFR279C \\
\hline UDP-glucose pyrophosphorylase & UGP1, YHL012W & AGL082W \\
\hline Phosphoglucose isomerase & PGI1 & AEL249C \\
\hline \multicolumn{3}{|l|}{ Synthesis of the dolicholphosphate linked N-glycan precursor $\mathrm{Glc}_{3} \mathrm{Man}_{9} \mathrm{GlcNAc}_{2}$} \\
\hline Dolichol kinase & SEC59 & ABR051C \\
\hline Dolichol-phosphate-mannose (Dol-P-mannose) synthase & DPM1 & AEL275C \\
\hline Putative Dol-P-mannose biosynthesis regulatory (DPM2) protein & YIL102C-A & ACR063W-A \\
\hline UDP- $N$-acetylglucosamine-1-phosphate transferase & ALG7 & AFL037W \\
\hline UDP- $N$-acetylglucosamine transferase: catalytic subunit & ALG13 & AGL042W \\
\hline UDP- $N$-acetylglucosamine transferase: transmembrane part & ALG14 & AGL202W \\
\hline GDP-mannose:GlcNAc 2 -PP-Dol $\beta 1,4$-mannosyltransferase & ALG1 & $A D L 338 C$ \\
\hline GDP-mannose:Man ${ }_{1 / 2}$ GlcNAc $_{2}$-PP-Dol $\alpha 1,3 / 1,6$-mannosyltransferase & ALG2 & AFL098W \\
\hline GDP-mannose:Man ${ }_{3 / 4} G_{c N} A_{2}$-PP-Dol $\alpha 1,2$-mannosyltransferase & ALG11 & $A D L 235 W$ \\
\hline Protein required for translocation of $\mathrm{Man}_{5} \mathrm{GlcNac}_{2}$-PP-Dol to the lumenal side of the ER & RFT1 & AFR015W \\
\hline Dol-P-mannose:Man ${ }_{5} \mathrm{GlcNAc}_{2}$-PP-Dol $\alpha 1,3$-mannosyltransferase & ALG3 & AGL299C \\
\hline Dol-P-mannose:Man ${ }_{6 / 8} \mathrm{GlcNAc}_{2}$-PP-Dol $\alpha 1,2$-mannosyltransferase & ALG9 & ABL185C \\
\hline Dol-P-mannose:Man ${ }_{7} \mathrm{GlNAC}_{2}$-PP-Dol $\alpha 1,6$-mannosyltransferase & ALG12 & AAR043C \\
\hline Dolichol-phosphate $\beta$-glucosyltransferase & ALG5 & AFL133C \\
\hline Dol-P-glucose:Man ${ }_{9} \mathrm{GlcNAc}_{2}$-PP-Dol $\alpha 1,3$-glucosyltransferase & ALG6 & ACR004W \\
\hline Dol-P-glucose:Glc1Man ${ }_{9} \mathrm{GlcNAc}_{2}$-PP-Dol $\alpha 1,3$-glucosyltransferase & ALG8 & $A D R 210 C$ \\
\hline Dol-P-glucose:Glc ${ }_{2} \mathrm{Man}_{9} \mathrm{GlcNAc}_{2}$-PP-Dol $\alpha 1,2$-glucosyltransferase & DIE2/ALG10 & $A D L 138 C$ \\
\hline Dolichol pyrophosphate phosphatase & CAX4/CWH8 & ACL186W \\
\hline \multicolumn{3}{|l|}{ Oligosaccharyltransferase (OST) subunits } \\
\hline Subunit of the OST complex & OST4 & ABL170C \\
\hline Beta subunit of the OST complex & WBP1 & ADL003C \\
\hline Zeta subunit of the OST complex & OST5 & AFR241W \\
\hline Alpha subunit of the OST complex-Ribophorin I & OST1 & AAL170W \\
\hline Subunit of the OST complex & OST6 & AER330W \\
\hline Delta subunit of the OST complex-Ribophorin II & SWP1 & ADR268W \\
\hline Gamma subunit of the OST complex & OST3 & AER413C \\
\hline Epsilon subunit of the OST complex & OST2 & ADL261C \\
\hline Subunit of the OST complex & STT3 & AFR491W \\
\hline \multicolumn{3}{|l|}{ Processing of the $\mathrm{N}$-glycan precursor $\mathrm{Gl}_{3} \mathrm{Man}_{9} \mathrm{GlcNAc}_{2}$ after transfer to a polypeptide } \\
\hline Processing alpha glucosidase I & CWH41 & AFR483C \\
\hline Glucosidase II-alpha subunit & ROT2 & AAR173C \\
\hline Glucosidase II-beta subunit & GTB1 & AGR178W \\
\hline$\alpha 1,2$-mannosidase & MNS1 & AER165W \\
\hline Putative $\alpha$-mannosidase $\rightarrow$ GH92 family member & No homolog & ADR339C \\
\hline a1,2-mannosidase-like protein (ER degradation enhancer) & MNL1/HTM1 & ADL390W \\
\hline Putative mannosidase involved in ER-associated protein degradation & YLR057W/MNL2 & ACR213W \\
\hline \multicolumn{3}{|l|}{ Golgi } \\
\hline Initiating $\alpha 1,6$-mannosyltransferase & $\mathrm{OCH} 1$ & AFR465C \\
\hline Subunit of the Golgi $\alpha 1,6$-mannosyltransferase complexes M-Pol I and M-Pol II & MNN9 & AGL259C \\
\hline Subunit of the Golgi $\alpha 1,6$-mannosyltransferase complex M-Pol I & VAN1 & $A B L 124 W$ \\
\hline Subunit of the Golgi $\alpha 1,6$-mannosyltransferase complex M-Pol II & MNN10 & AFR454W \\
\hline Subunit of the Golgi $\alpha 1,6$-mannosyltransferase complex M-Pol II & MNN11 & $A E L 142 W$ \\
\hline Subunit of the Golgi $\alpha 1,6$-mannosyltransferase complex M-Pol II & ANP1 & AFR357W \\
\hline Subunit of the Golgi $\alpha 1,6$-mannosyltransferase complex M-Pol II & HOC1 & AFR435W \\
\hline$\alpha 1,2$-mannosyltransferase & MNN2 & AER018C, AEL082W \\
\hline a1,2-mannosyltransferase & MNN5 & AEL148W \\
\hline Putative $\alpha 1,2$-mannosyltransferase and/or mannosylphosphate transferase & KRE2/MNT1, KTR6/MNN6 & AGL267C \\
\hline Putative positive regulator of the mannosylphosphate transferase & MNN4, YJR061W & AFR416C \\
\hline Golgi $\alpha 1,3$-mannosyltransferase & MNT3, MNN1 & AFL235W \\
\hline
\end{tabular}


Table 1 (continued)

\begin{tabular}{|c|c|c|}
\hline Predicted protein function & S. cerevisiae gene & A. gossypii gene \\
\hline$\alpha 1,2$-mannosyltransferase & KTR1 & $A D L 265 W-A$ \\
\hline$\alpha 1,2$-mannosyltransferase & KTR2, YUR1 & ACR251C \\
\hline Putative $\alpha 1,2$-mannosyltransferase & KTR3 & ADR048W \\
\hline Putative mannosyltransferase & KTR4 & AEL243W \\
\hline \multicolumn{3}{|l|}{ Cytosol and vacuole } \\
\hline Vacuolar $\alpha$-mannosidase, involved in free oligosaccharide degradation & AMS1 & AGR385C \\
\hline \multicolumn{3}{|l|}{ Unknown } \\
\hline Putative endo- $\beta$ - $N$-acetylglucosaminidase $\rightarrow$ GH85 family member & No homolog & AFR597W \\
\hline
\end{tabular}

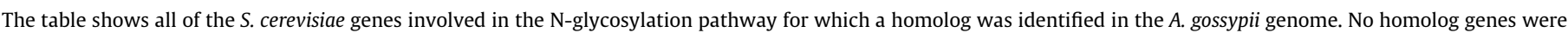

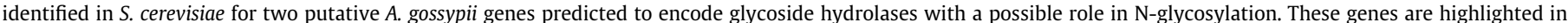
bold.
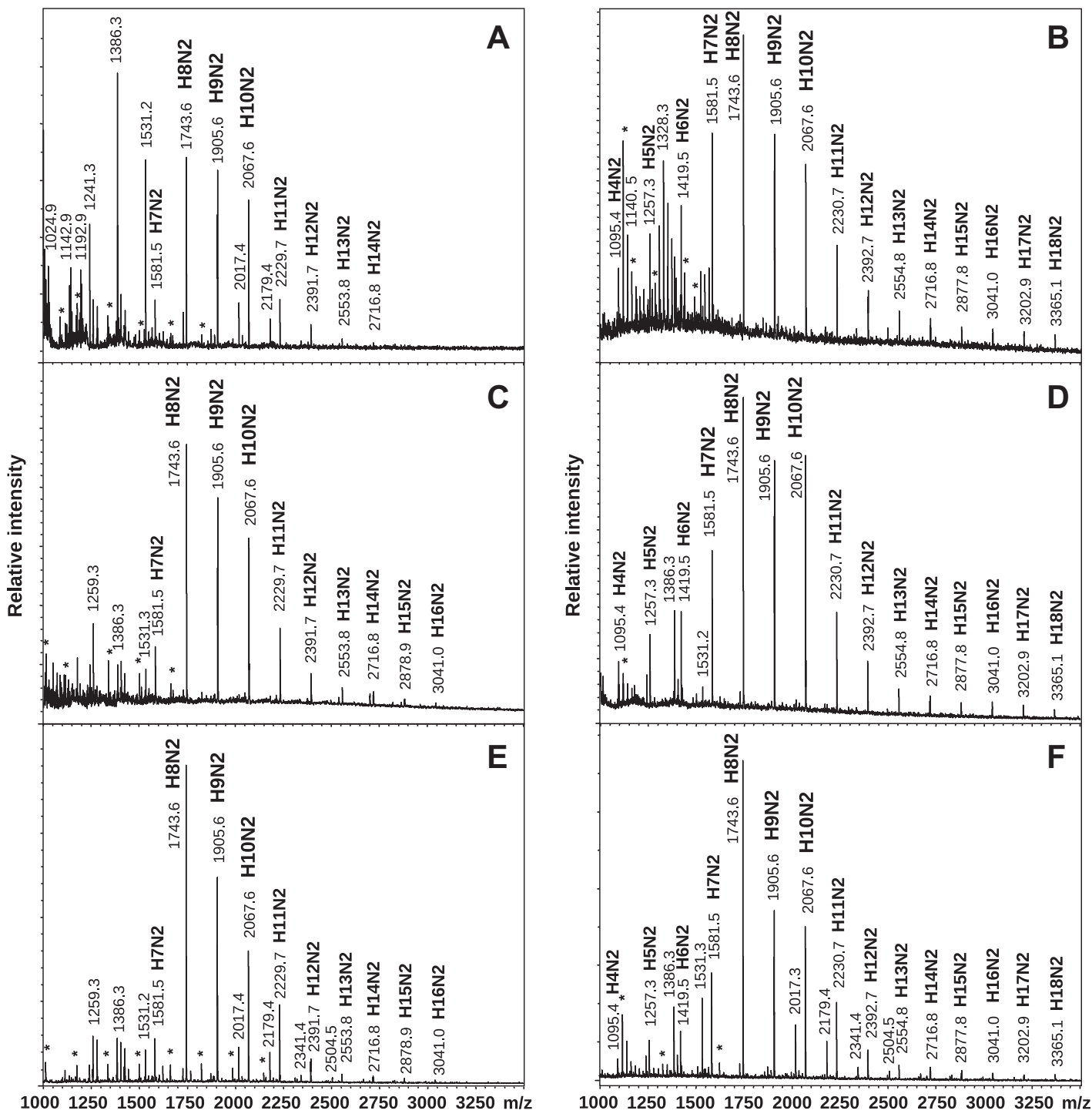

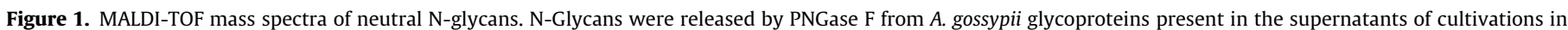

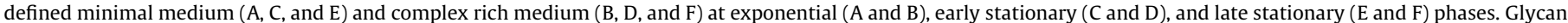

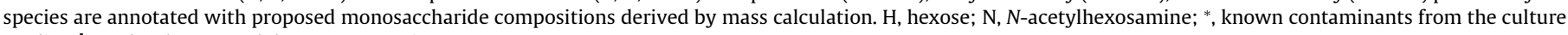
media; $\downarrow$, and unknown polyhexose contaminants.

adduct ions of high-mannose type $\mathrm{N}$-glycans containing two phosphate/sulfate residues and only one $\mathrm{N}$-acetylhexosamine (P2H5N1 to $P 2 \mathrm{H} 8 \mathrm{~N} 1)$. The $m / z$ values of another series of minor peaks observed at $160 \mathrm{~m} / \mathrm{z}$ intervals (indicated with arrows in Fig. 2) corresponded to diphosphorylated/disulfated $\mathrm{N}$-glycans in the range P2H3N2 to P2H16N2.

\subsection{Structural analysis of $A$. gossypii N-glycans by NMR spectroscopy}

A mixture of $\mathrm{N}$-glycans concentrated from the supernatant of mycelia grown in defined minimal medium until late stationary phase was analyzed by NMR spectroscopy, which yielded 


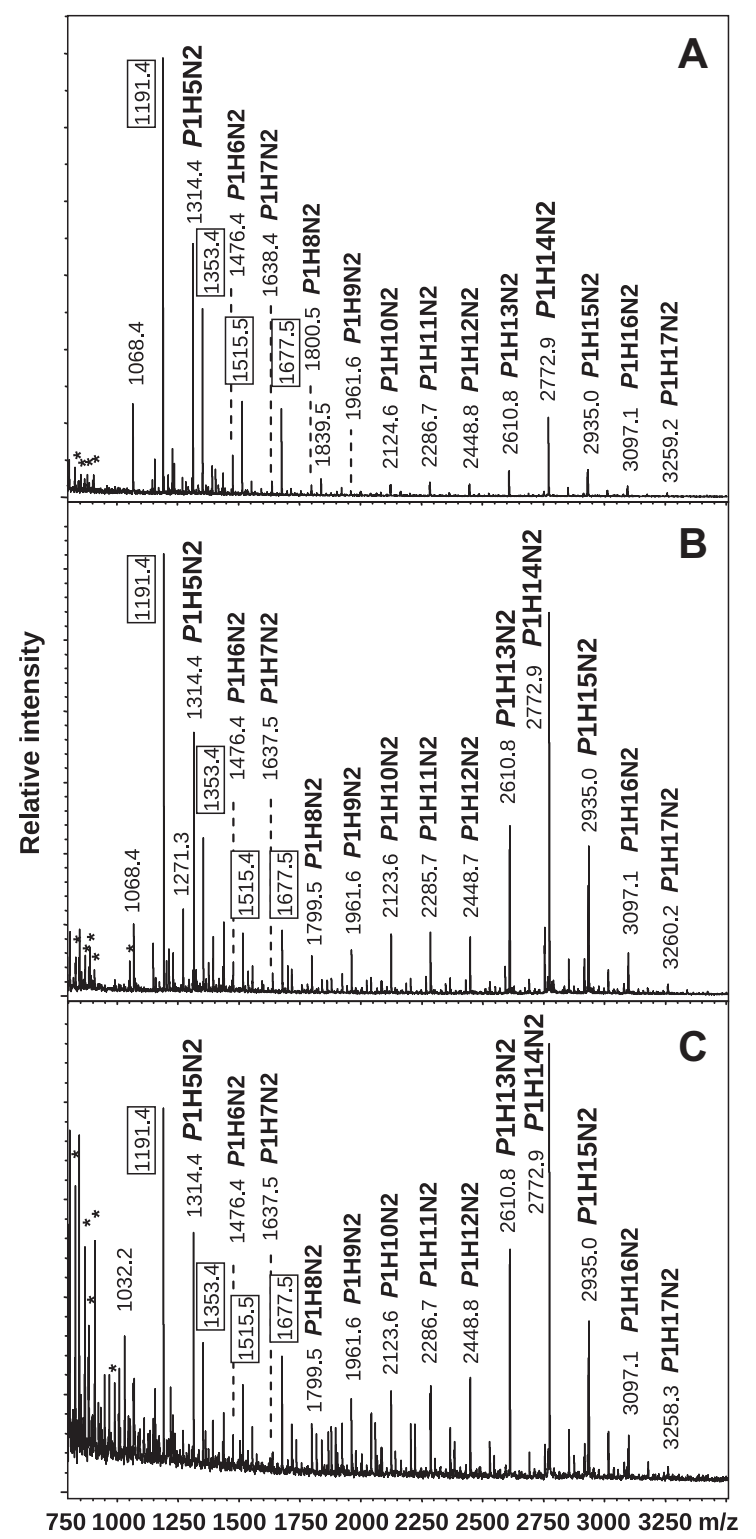

Figure 2. MALDI-TOF mass spectra of acidic N-glycans. N-Glycans were released by PNGase F from A. gossypii glycoproteins present in the supernatant of mycelia grown in defined minimal medium at exponential (A), early stationary (B), and late stationary (C) phases. Glycan species are annotated with proposed monosaccharide compositions derived by mass calculation and based on NMR data. $\mathrm{H}$, hexose; $\mathrm{N}, \mathrm{N}$ acetylhexosamine; $P$, phosphate; $\downarrow$, glycans containing two phosphate residues; $\square$, glycans containing two phosphate residues and only one $\mathrm{N}$-acetylhexosamine; *, known contaminants from the culture media.

substantial data about the most abundant N-glycan structures present. Figure $3 \mathrm{~B}$ and $\mathrm{C}$ show the anomeric region and the methyl signals of the $N$-acetyl (NAc) groups of the $1 \mathrm{D}^{1} \mathrm{H}$ NMR spectrum obtained, respectively, and Table 2 indicates the chemical shift values of the various structural reporter group signals that, despite the complexity of the mixture, remained individually observable.

The $1 \mathrm{D}^{1} \mathrm{H}$ NMR spectrum revealed proton signals consistent with a mixture of high-mannose type $\mathrm{N}$-glycans with an average of eight $\alpha$-mannoses per molecule plus the $\beta$-mannose linked to the $N, N^{\prime}-$ diacetylchitobiose core $\left(\mathrm{Man}_{9} \mathrm{GlcNAc}_{2}\right)$, as estimated by integration of the structural reporter group indicator signals. The following glycosidic linkages were found from the spectral interpretation in A. gossypii N-glycans: $\operatorname{Man}-\mathbf{4}(\alpha 1,3)\left[\operatorname{Man}-\mathbf{4}^{\prime}(\alpha 1,6)\right] \operatorname{Man}-\mathbf{3}(\beta 1,4)$ GlcNAc-2 $(\beta 1,4)$ GlcNAc-1, Man-A( $\alpha 1,3)[$ Man-B( $\alpha 1,6)]$ Man-4', Man-
D2 $(\alpha 1,2)$ Man-A, Man-D3( $\alpha 1,2)$ Man-B, Man-C( $\alpha 1,2)$ Man-4, Man$\mathbf{C}^{\prime}(\alpha 1,6)$ Man-4, Man-D1( $\left.\alpha 1,2\right)$ Man-C, Man-D4( $(\alpha 1,2) / \mathbf{D 5}(\alpha 1,6)$ Man$\mathbf{C}^{\prime}$, and $\operatorname{Man}(\alpha 1-\boldsymbol{P}-6)$.

The $\mathrm{H}-1$ signals of the two anomers of the reducing end GlcNAc1 were found at $5.187(\alpha)$ and $4.697(\beta)$ ppm, and the methyl proton resonance of its NAc group at $2.038 \mathrm{ppm}$. The characteristic $\mathrm{H}-1$ signal of the second GlcNAc-2 was detected at $4.60 \mathrm{ppm}$ and its NAc signals at 2.064, 2.068, and $2.077 \mathrm{ppm}$, reflecting the structural heterogeneity of the sample. At $10^{\circ} \mathrm{C}$, the $\mathrm{H}-1$ signal for the mannose $\beta 1$,4-linked to GlcNAc (Man-3) was found at the expected position $4.774 \mathrm{ppm}$, overlapped with the residual water signal at $25^{\circ} \mathrm{C}$.

All other major peaks observed in the ${ }^{1} \mathrm{H}$ NMR spectrum on the left side of the water signal were assigned to $\mathrm{H}-1$ proton signals of $\alpha$-mannoses. These assignments were confirmed by 2D NMR experiments, where scalar couplings to characteristic $\mathrm{H}-2$ protons of the mannoses could be observed (not shown). The set of chemical shifts typical of the H-l protons of the $\alpha 1,6$-linked Man- $\mathbf{4}^{\prime}$ in the trimannosyl $N, N^{\prime}$-diacetylchitobiose core gave signals in two areas. The first group of $\mathrm{H}-\mathrm{l}$ signals could be found at $4.87 \mathrm{ppm}$, which is indicative of a substitution of Man- $\mathbf{4}^{\prime}$ by an $\alpha 1,3$-linked Man-A, or possibly by an $\alpha 1,6$-linked Man-B. In addition, a group of three $\mathrm{H}-1$ signals arising from $\alpha 1,6$-linked mannoses was found at $4.905,4.917$, and $4.929 \mathrm{ppm}$. The $4.917 \mathrm{ppm}$ signal was consistent with the presence of Man-4/29,30 and/or Man-D5 ${ }^{31}$ at a terminal position, and the $4.905 \mathrm{ppm}$ signal with a terminal Man-B in $\alpha 1,6$-linkage to Man-4. ${ }^{29,30}$ The minor $\mathrm{H}-1$ signal at $4.929 \mathrm{ppm}$ was consistent with Man- $\mathbf{C}^{\prime}$ and/or Man-D5 occurring in a terminal position. ${ }^{31,32} \mathrm{H}-1$ signals consistent with internal Man-B substituted by a terminal $\alpha 1,2$-linked Man-D3 were found at $5.141 \mathrm{ppm}$. Proton signals from Man-A $\propto 1,3$-linked to Man-4' ${ }^{\prime}$ were also found. The signal at $5.400 \mathrm{ppm}$ indicated the substitution of Man-A with an $\alpha 1,2$-linked Man-D2. The group of $\mathrm{H}-1$ signals at $5.08-5.11 \mathrm{ppm}$ resonates in an area that is characteristic of an $\alpha 1,3-$ linked Man-A or Man-4 occurring in a terminal position. ${ }^{29,30,32,33}$

Chemical shifts typical of the H-l protons from $\alpha 1,3$-linked Man-4 from the trimannosyl $N, N^{\prime}$-diacetylchitobiose core were also observed at $5.337 \mathrm{ppm}$, indicating the presence of Man-C $\alpha 1,2-$ linked to Man-4. A major signal found at $5.30 \mathrm{ppm}$ corresponded to a Man-C residue bearing an $\alpha 1,2$-linked Man-D1 residue. The $\mathrm{H}-1$ and $\mathrm{H}-2$ resonances of all terminal $\alpha 1,2$-linked mannoses were found in the same area (H-1 5.05 ppm and H-2 4.072 ppm), being impossible to distinguish between their signals. The major $\mathrm{H}-1$ signal at $5.120 \mathrm{ppm}$ was consistent with the presence of internal Man- $\mathbf{C}^{\prime}$ and/or Man-D5 substituted by an $\alpha 1,2$ - and/or $\alpha 1,6$-linked mannose. ${ }^{31,32}$

The signals found at 5.486 and $5.448 \mathrm{ppm}$ were consistent with the presence of $\alpha$-mannosylphosphate (Man-P) groups. ${ }^{31,34}$ The $^{31} \mathrm{P}$ decoupled ${ }^{1} \mathrm{H}$ spectrum (not shown) clearly showed that these signals were affected by the decoupling, confirming that they represented protons at the sites of phosphorylation. The remaining homonuclear coupling constant of these signals was smaller than $3 \mathrm{~Hz}$, confirming that they originate from mannoses. The phosphorylation was further confirmed by a ${ }^{1} \mathrm{H}^{31} \mathrm{P}$ HSQC experiment (Fig. 4), where cross peaks were observed between these proton signals and ${ }^{31} \mathrm{P}$ atoms resonating at two different frequencies. However, no cross peaks were detected at these ${ }^{31} \mathrm{P}$ chemical shifts to any other protons. Therefore, the site of phosphorylation could not be determined. In addition to these two proton signals, a weak signal at $5.416 \mathrm{ppm}$ was also affected by the ${ }^{31} \mathrm{P}$ decoupling, but was not detected in the HSQC spectrum, probably due to low abundance. In agreement with the MALDI-TOF results, the relative low intensities of the Man-P H-1 signals support the presence of phosphorylated N-glycan structures predominantly containing only one phosphate residue. 

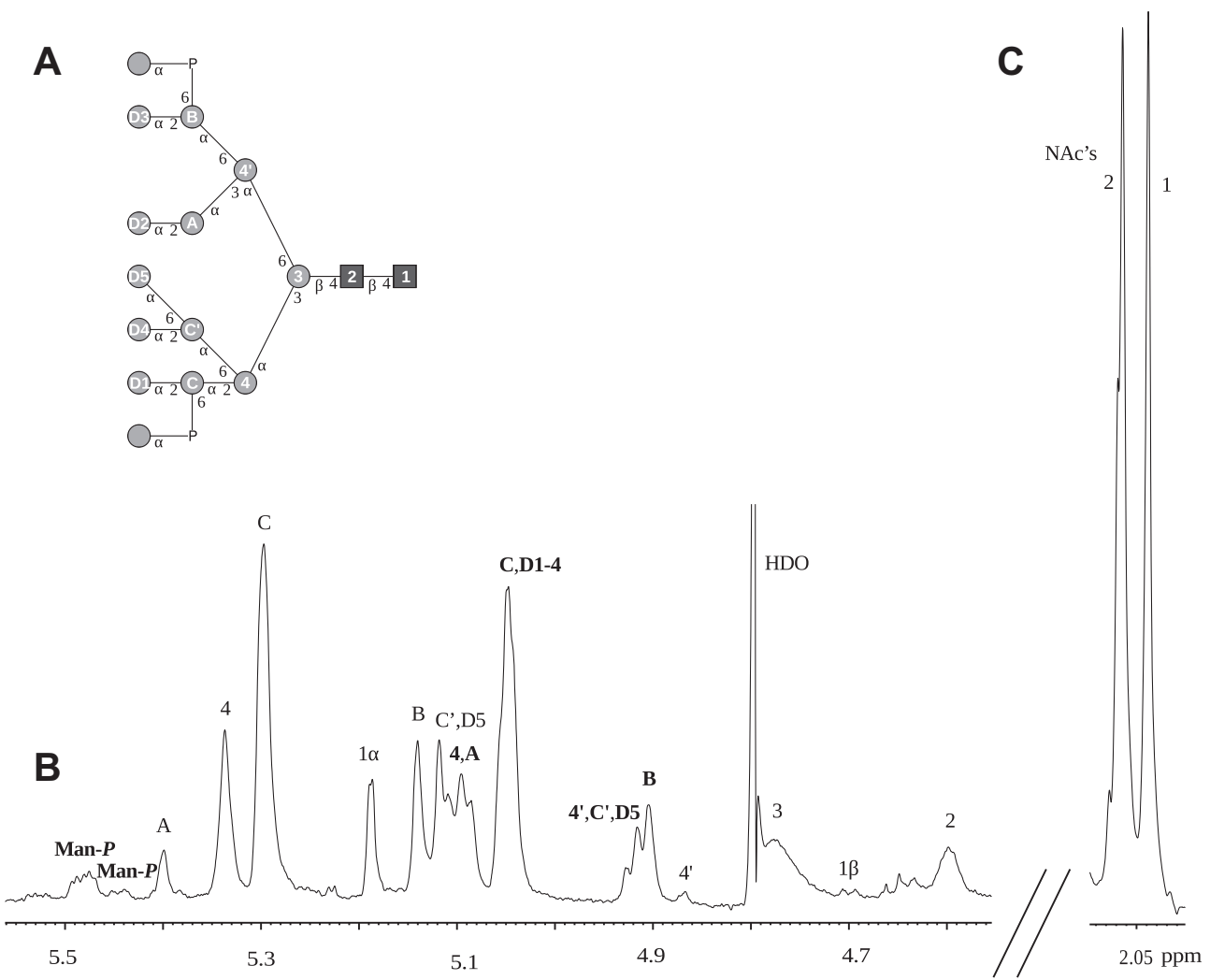

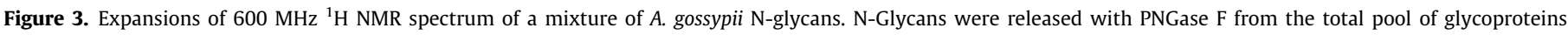

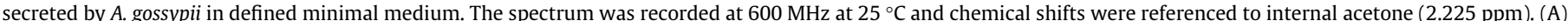

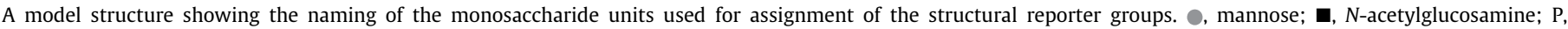

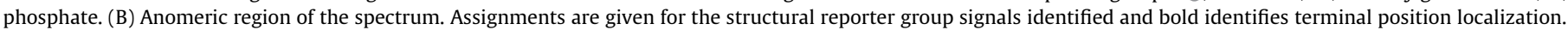
(C) Methyl signals of the NAc groups of the two reducing end GlcNAc units.

Chemical shifts typical of the $\mathrm{H}-1$ and $\mathrm{H}-2$ protons of $\alpha 1,3-$ mannose extensions at Man-D1 and Man-D3, like those reported for $S$. cerevisiae $\mathrm{N}$-glycans ${ }^{33}$, were not detected, as no $\mathrm{H}-1 / \mathrm{H}-2$ correlation was found at 5.140-5.144/4.224-4.226 ppm. ${ }^{31,33}$ No evidence was obtained for the presence of sulfate. Sulfatation usually leads to large shifts of the ${ }^{1} \mathrm{H}$ NMR signals, and such shifts were absent. Fucose in either $\alpha 1,3-, \alpha 1,4-$ or $\alpha 1,6$-linkage to GlcNAc residues was also undetectable, by virtue of the absence of fucose methyl groups in the region of the $1.17-1.28$ ppm. ${ }^{29,35}$ Nevertheless, due to the low detection limit of NMR, the presence of small amounts of glycan structures containing these or other residues cannot be ruled out.

\section{Discussion}

The data presented in this study represent the first characterization of the $\mathrm{N}$-glycans synthesised by $A$. gossypii. Here, we demonstrate that $A$. gossypii secreted proteins carry high-mannose type $\mathrm{N}$-glycan structures in the range $\mathrm{Man}_{4-18} \mathrm{GlcNAc}_{2}$, predominantly with neutral core-type $\mathrm{Man}_{8-10} \mathrm{GlcNAc}_{2} \mathrm{~N}$-glycans not terminally capped by $\alpha 1,3$-linked mannose residues. A. gossypii also produces acidic mannosylphosphorylated N-glycan structures that, depending on the growth conditions, can be predominantly longer than the neutral structures ( $\left.\operatorname{Man}_{13-14} P \mathrm{GlNAC}_{2}\right)$.

In eukaryotes, the $\mathrm{N}$-glycan biosynthetic pathway begins with the synthesis of the precursor N-glycan $\mathrm{Glc}_{3} \mathrm{Man}_{9} \mathrm{GlcNAc}_{2}$ and its transfer by the oligosaccharyltransferase complex to the amino group of asparagine residues of nascent polypeptides entering the ER. ${ }^{13}$ Subsequent trimming of the precursor N-glycan by glucosidases I and II and a specific ER-residing $\alpha 1,2$-mannosidase lead to the formation of a core glycan $\left(\mathrm{Man}_{8} \mathrm{GlcNAc}_{2}\right){ }^{17}$ Glycoproteins containing $\mathrm{Man}_{8} \mathrm{GlcNAc}_{2}$ (or Man ${ }_{9} \mathrm{GlcNAc}_{2}$, in Schizosaccharomyces pombe and Kluyveromyces lactis) are then transported to the Golgi apparatus. ${ }^{16,17}$

Most yeast do not trim the precursor $\mathrm{Glc}_{3} \mathrm{Man}_{9} \mathrm{GlcNAc}_{2}$ shorter than the core $\mathrm{Man}_{8} \mathrm{GlcNAc}_{2}$, unlike mammalian cells and filamentous fungi. However, small amounts of $\mathrm{N}$-glycans smaller than $\mathrm{Man}_{8} \mathrm{GlcNAc}_{2}$ have also been found in some wild-type yeast. NGlycans in the range $\mathrm{Man}_{5-7} \mathrm{GlcNAc}_{2}$ were found in Cryptococcus neoformans cell wall and secreted proteins, ${ }^{36} \operatorname{Man}_{6-7} \mathrm{GlcNAc}_{2} \mathrm{~N}-$ glycans were detected in recombinant aspartic protease produced by Pichia pastoris, ${ }^{37}$ and N-glycans with the composition Man ${ }_{7}$ Glc$\mathrm{NAc}_{2}$ were detected in Hansenula polymorpha ${ }^{38}$ and Yarrowia lipolytica $^{39}$ secreted proteins. Filamentous fungi, on the other hand, predominantly produce mammalian high-mannose type (Man ${ }_{5-9}$ GlcNAc $_{2} \mathrm{~N}$-glycan structures. ${ }^{40,41}$ They usually possess two types of $\alpha 1,2$-mannosidases: one residing in the ER, like that found in yeast, and which trims $\mathrm{Man}_{9} \mathrm{GlcNAc}_{2}$ to $\mathrm{Man}_{8} \mathrm{GlcNAc}_{2}$, and another that resembles the mammalian Golgi $\alpha 1,2$-mannosidases, which trims $\mathrm{Man}_{8} \mathrm{GlcNAc}_{2}$ to $\mathrm{Man}_{5} \mathrm{GlcNAc}_{2}$. ${ }^{16}$

$\mathrm{N}$-Glycans smaller than the core $\mathrm{Man}_{8} \mathrm{GlcNAc}_{2}$ were also found in A. gossypii, especially when it was grown in complex rich medium. This suggests that trimming of the core $\mathrm{Man}_{8} \mathrm{GlcNAc}_{2} \mathrm{~N}$-glycan may occur in $A$. gossypii. Genomic analysis indicated that $A$. gossypii has a glycosylation machinery very similar to that of $S$. cerevisiae (Table 1), but also revealed a putative Golgi-localized $\alpha$-mannosidase of the glycoside hydrolase family 92 (GH92), encoded by the $A$. gossypii $A D R 339 C$ gene, for which there is no homolog in $S$. cerevisae. The potential role of this putative enzyme on $\mathrm{N}$-glycan trimming in A. gossypii is a matter of further study. 
Table 2

${ }^{1} \mathrm{H}$ chemical shifts of the structural reporter group protons of the constituent monosaccharides of $A$. gossypii $N$-glycans

\begin{tabular}{|c|c|c|c|}
\hline \multicolumn{3}{|c|}{ Glycan residue } & \multirow{2}{*}{$\begin{array}{l}{ }^{1} \mathrm{H} \text { NMR chemical shift } \\
\text { Observed }\end{array}$} \\
\hline Residue & Linkage & Proton & \\
\hline \multirow[t]{3}{*}{ GlcNAc-1 } & & $\mathrm{H}-1 \alpha$ & 5.187 \\
\hline & & $\mathrm{H}-1 \beta$ & 4.697 \\
\hline & & NAc & 2.038 \\
\hline \multirow[t]{2}{*}{ GlcNAc-2 } & 4 & $\mathrm{H}-1$ & 4.600 \\
\hline & & NAc & $2.064,2.068$ and 2.077 \\
\hline \multirow[t]{2}{*}{ Man-3 } & 4,4 & $\mathrm{H}-1$ & 4.774 \\
\hline & & $\mathrm{H}-2$ & n.d. \\
\hline \multirow[t]{2}{*}{ Man-4' } & $6,4,4$ & $\mathrm{H}-1$ & $4.917^{*} / 4.87$ \\
\hline & & $\mathrm{H}-2$ & $3.99 * / 4.144$ \\
\hline \multirow[t]{2}{*}{ Man-B } & $6,6,4,4$ & $\mathrm{H}-1$ & $4.905^{*} / 5.141$ \\
\hline & & $\mathrm{H}-2$ & $3.99 * / 4.02$ \\
\hline \multirow{2}{*}{ Man-A } & $3,6,4,4$ & $\mathrm{H}-1$ & $5.08-5.11^{*} / 5.400$ \\
\hline & & $\mathrm{H}-2$ & $4.01 * / 4.009$ \\
\hline \multirow[t]{2}{*}{ Man-4 } & $3,4,4$ & $\mathrm{H}-1$ & $5.08-5.11^{*} / 5.337$ \\
\hline & & $\mathrm{H}-2$ & $4.01 * / 4.089$ \\
\hline \multirow[t]{2}{*}{ Man-C } & $2,3,4,4$ & $\mathrm{H}-1$ & $5.05 * / 5.30$ \\
\hline & & $\mathrm{H}-2$ & $4.072^{*} / 4.112$ \\
\hline Man-D1, & $2,2,3,4,4$ & $\mathrm{H}-1$ & $5.05^{*}$ \\
\hline Man-D2, & $2,3,6,4,4$ & & \\
\hline Man-D3 or & $2,6,6,4,4$ or & $\mathrm{H}-2$ & $4.072^{*}$ \\
\hline Man-D4 & $2,6,3,4,4$ & & \\
\hline \multirow[t]{2}{*}{ Man-C' } & $6,3,4,4$ & $\mathrm{H}-1$ & $4.929^{*} / 5.120$ \\
\hline & & $\mathrm{H}-2$ & $3.99 * / 4.070$ \\
\hline \multirow[t]{2}{*}{ Man-D5 } & $6,6,3,4,4$ & $\mathrm{H}-1$ & $4.929^{*} / 4.917^{*} / 5.120$ \\
\hline & & $\mathrm{H}-2$ & $3.99 * / 4.070$ \\
\hline Man-P & n.d. & $\mathrm{H}-1$ & $5.486,5.448$ and 5.416 \\
\hline
\end{tabular}

Assignments were made by comparison with NMR data reported in the literature for several $\mathrm{N}$-glycan structures and supported by $2 \mathrm{D}$ homonuclear ${ }^{1} \mathrm{H}-{ }^{1} \mathrm{H}$ DQF-COSY and ${ }^{1} \mathrm{H}-{ }^{1} \mathrm{H}$ TOCSY experiments. The identified signals were consistent with highmannose type $\mathrm{N}$-glycan structures with average monosaccharide composition $\mathrm{Man}_{9} \mathrm{GlCNAC}_{2}$.

* Corresponding to residue in a terminal position

n.d. not determined.

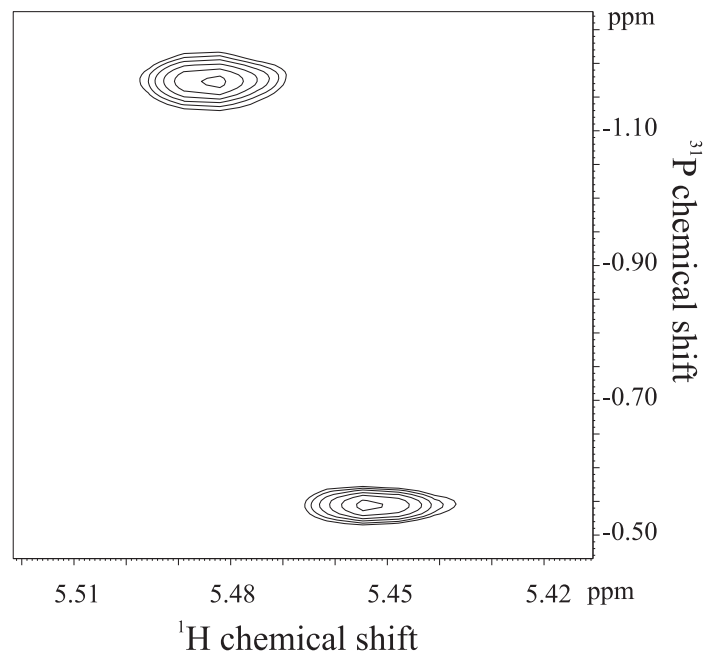

Figure 4. Expansion of ${ }^{1} \mathrm{H}^{3}{ }^{31} \mathrm{P}$ HSQC spectrum of a mixture of A. gossypii N-glycans. $\mathrm{N}$-Glycans were released from the total pool of glycoproteins secreted by A. gossypii in defined minimal medium by PNGase F digestion. The spectrum shows the cross peaks between Man $\mathrm{H}-1$ and the phosphate groups.

In yeast, processing in the Golgi involves the addition of an $\alpha 1,6$-mannose residue by the Och 1 protein. This branch is then elongated by the stepwise addition of mainly mannose residues, leading to the formation of small core-type $\left(\mathrm{Man}_{8-14} \mathrm{GlcNAc}_{2}\right)$ or large hypermannosylated mannan-type $\left(\mathrm{Man}_{>15} \mathrm{GlCNAc}_{2}\right)$ outer chains. ${ }^{17}$ Hypermannosylation is not a typical feature of filamentous fungi, ${ }^{15}$ although it may occur if Och1 activity is present. ${ }^{10,42}$
A. gossypii produced small amounts of N-glycan structures containing more than 15 hexoses (Figs. 1 and 2). Moreover, proton signals consistent with the presence of $\alpha 1,6$-mannose extensions from the $\alpha 1,3$-mannose residue of the trimannosyl $N, N^{\prime}$-diacetylchitobiose core were detected by NMR, indicating that outer chain processing of $\mathrm{N}$-glycans occurred in A. gossypii. Indeed homologs are found in its genome for all S. cerevisiae genes known to be involved in outer chain biosynthesis (Table 1 ). However, our results indicate that outer chain processing differs considerably in A. gossypii and in $S$. cerevisiae, since shorter $\mathrm{N}$-glycans were predominantly produced by A. gossypii when comparing to S. cerevisiae. ${ }^{33,37,43}$ These were more similar in extent to those produced by nonconventional yeast species such as the methylotrophic species P. pastoris ${ }^{31,37,44}$ and $H$. polymorpha, ${ }^{38}$ and the dimorphic yeast $Y$. lipolytica. ${ }^{39}$

$S$. cerevisiae usually adds terminal $\alpha 1,3$-linked mannoses to its $\mathrm{N}$-glycans through the action of Mnn1p. ${ }^{17}$ The A. gossypii gene AFL235W is a nonsyntenic homolog of the S. cerevisiae MNT3 and MNN1 genes, with a higher degree of homology to MNT3 than to MNN1. Both genes encode $\alpha 1,3$-mannosyltransferases in S. cerevisi$a e$, but Mnt3p has only been described as involved in 0 -glycosylation. ${ }^{45}$ In this study, no terminal $\alpha 1,3$-mannose caps were detected in A gossypii N-glycans by NMR. Therefore, given that only the most abundant sugar species can be detected by this technique, extensive $\alpha 1,3$-mannose capping did not occur in A. gossypii.

$\mathrm{N}$-Glycans may be further modified by the addition of acidic phosphate groups in yeast and other fungi. ${ }^{15,17} \mathrm{~A}$. gossypii also added phosphate groups to its N-glycans (Figs. 2 and 3). In S. cerevisiae,$^{34}$ P. pastoris, ${ }^{31}$ and Trichoderma reese ${ }^{46}$ glycoproteins, Man-P extensions occur on $0-6$ of Man-B and/or Man-C (in T. reesei only on Man-B) within the $\mathrm{N}$-glycan chain. In this study, two rather strong proton signals with different chemical shifts representing phosphorylation sites were detected by NMR in A. gossypii N-glycans (Fig. 3), however the site(s) of phosphorylation could not be determined.

The extent of mannosylphosphorylation in P. pastoris ${ }^{37}$ and $T$. reese ${ }^{40}$ depends on culture conditions, including medium composition and $\mathrm{pH}$. In S. cerevisiae, mannosylphosphorylation is related to a cellular stress response, increasing under conditions of high osmolarity and in late exponential and stationary phases of growth. ${ }^{47,48}$ In this study, the culture conditions and cultivation stage also affected the extent of phosphorylation and extension of the A. gossypii N-glycans, highlighting the importance of these factors on the regulation of the N-glycosylation pathway in this fungus. Growth in defined minimal medium resulted in a lower specific growth rate and promoted more $\mathrm{N}$-glycan extension and mannosylphosphorylation than growth in a complex rich medium, especially during the stationary phase, as observed in S. cerevisiae. ${ }^{47}$ Similarly, T. reesei prominently mannosylphosphorylated cellobiohydrolase I (CBHI) under minimal growth conditions, but only at low $\mathrm{pH}^{40}$ This modification was proposed to be related to a stress response of $T$. reesei to the low $\mathrm{pH}$ conditions of the minimal medium. ${ }^{40}$ Here, the culture $\mathrm{pH}$ was kept constant at $6 \pm 0.1$ in all A. gossypii cultivations, so this should not have been the case in $A$. gossypii. However, in light of the observations made in S. cerevisiae, where mannosylphosphorylation was observed to occur in response to high osmolarity conditions, ${ }^{47}$ a lower osmoprotection offered by the minimal medium to A. gossypii cells in comparison to the rich medium may help explain why extensive mannosylphosphorylation only occurred under minimal growth conditions in A. gossypii.

When defined medium was used, diphosphorylated N-glycans containing only one $\mathrm{N}$-acetylglucosamine were detected by MALDI-TOF mass spectrometry, suggesting the presence of endo- $\beta-N$ acetylglucosaminidase (ENGase) activity in A. gossypii under these conditions. Single $\mathrm{N}$-acetylglucosamine residues are often found at the $\mathrm{N}$-glycosylation sites of $T$. reesei proteins. ${ }^{40}$ These have been 
attributed to the action of a GH18 family protein with extracellular ENGase-type activity. ${ }^{40,49}$ Mucor hiemalis also produces an ENGase, but of the GH85 family (Endo M), which catalyzes the release of $\mathrm{N}$-glycans with only one $\mathrm{N}$-acetylglucosamine residue at their reducing end, leaving one $N$-acetylglucosamine attached to the protein. ${ }^{50}$ The A. gossypii AFR597W gene, for which there is no homolog in S. cerevisiae, is predicted to encode a putative intracellular GH85 family ENGase, and we have observed that this gene is transcribed (unpublished data), indicating that it is probably expressed in A. gossypii. Thus, AFR597W is a good candidate ENGase for catalyzing the liberation of N-glycans containing only one $\mathrm{N}$-acetylglucosamine residue and details regarding its functionality warrant further investigation.

The N-glycan structures on A. gossypii secreted glycoproteins and the genomic information regarding their biosynthetic pathway indicate that protein glycosylation in A. gossypii is intermediate to that of S. cerevisiae and other filamentous fungi species. A. gossypii possibly trims $\mathrm{N}$-glycans as other filamentous fungi do, although it generally produces yeast-like $\mathrm{N}$-glycan structures slightly longer than those typical of filamentous fungi. Hypermannosylation occurs, but is more limited than in S. cerevisiae. Given these observations, it would be intriguing to elucidate in detail the A. gossypii $\mathrm{N}$-glycosylation pathway and investigate the role of glycosylation in the development of $A$. gossypii multicellular hyphae.

\section{Acknowledgments}

We thank Fundação para a Ciência e a Tecnologia (FCT), Portugal, for financial support through the project AshByofactory (PTDC/ EBB-EBI/101985/2008-FCOMP-01-0124-FEDER-009701) and MITPortugal Program (Ph.D. grant SFRH/BD/39112/2007 to Tatiana Q. Aguiar). We also thank Dr. Olli Aitio (University of Helsinki) for helpful assistance in the interpretation of the NMR data.

\section{References}

1. Dietrich, F. S.; Voegeli, S.; Brachat, S.; Lerch, A.; Gates, K.; Steiner, S.; Mohr, C.; Pöhlmann, R.; Luedi, P.; Choi, S.; Wing, R. A.; Flavier, A.; Gaffney, T. D.; Philippsen, P. Science 2004, 304, 304-307.

2. Stahmann, K. P.; Revuelta, J. L.; Seulberger, H. Appl. Microbiol. Biotechnol. 2000, 53, 509-516.

3. Wendland, J.; Walther, A. Nat. Rev. Microbiol. 2005, 3, 421-429.

4. Schmitz, H. P.; Philippsen, P. Fungal Biol. 2011, 115, 557-568.

5. Ribeiro, O.; Wiebe, M.; Ilmén, M.; Domingues, L.; Penttilä, M. Appl. Microbiol. Biotechnol. 2010, 87, 1437-1446.

6. Conesa, A.; Punt, P. J.; van Luijk, N.; van den Hondel, C. A. Fungal Genet. Biol. 2001, 33, 155-171.

7. Shoji, J. Y.; Arioka, M.; Kitamoto, K. Biotechnol. Lett. 2008, 30, 7-14.

8. Hayakawa, Y.; Ishikawa, E.; Shoji, J. Y.; Nakano, H.; Kitamoto, K. Mol. Microbiol. 2011, 81, 40-55.

9. Potter, B. A.; Hughey, R. P.; Weisz, O. A. Am. J. Physiol. Cell Physiol. 2006, 290, C1C10.

10. Kotz, A.; Wagener, J.; Engel, J.; Routier, F. H.; Echtenacher, B.; Jacobsen, I.; Heesemann, J.; Ebel, F. PLoS One 2010, 5, e15729.

11. Motteram, J.; Lovegrove, A.; Pirie, E.; Marsh, J.; Devonshire, J.; van de Meene, A.; Hammond-Kosack, K.; Rudd, J. J. Mol. Microbiol. 2011, 81, 415-433.

12. Jin, C. Int. J. Microbiol. 2012, 2012, 654251.

13. Helenius, A.; Aebi, M. Annu. Rev. Biochem. 2004, 73, 1019-1049.

14. Stolz, J.; Munro, S. J. Biol. Chem. 2002, 277, 44801-44808.
15. Maras, M.; van Die, I.; Contreras, R.; van den Hondel, C. A. Glycoconjugate J. 1999, 16, 99-107.

16. De Pourcq, K.; De Schutter, K.; Callewaert, N. Appl. Microbiol. Biotechnol. 2010, 87, 1617-1631.

17. Gemmill, T. R.; Trimble, R. B. Biochim. Biophys. Acta 1999, 1426, 227-237.

18. Deshpande, N.; Wilkins, M. R.; Packer, N.; Nevalainen, H. Glycobiology 2008, 18, 626-637.

19. Buser, R.; Lazar, Z.; Käser, S.; Künzler, M.; Aebi, M. J. Biol. Chem. 2010, 285, 10715-10723.

20. Grass, J.; Pabst, M.; Kolarich, D.; Pöltl, G.; Léonard, R.; Brecker, L.; Altmann, F. J. Biol. Chem. 2011, 286, 5977-5984.

21. Altmann-Jöhl, R.; Philippsen, P. Mol. Gen. Genet. 1996, 250, 69-80.

22. Verduyn, C.; Postma, E.; Scheffers, W. A.; Van Dijken, J. P. Yeast 1992, 8, 501517.

23. Wiebe, M. G.; Robson, G. D.; Shuster, J.; Trinci, A. P. Biotechnol. Bioeng. 2001, 73, $146-156$.

24. Hemmoranta, H.; Satomaa, T.; Blomqvist, M.; Heiskanen, A.; Aitio, O.; Saarinen, J.; Natunen, J.; Partanen, J.; Laine, J.; Jaatinen, T. Exp. Hematol. 2007, 35, 12791292.

25. Verostek, M. F.; Lubowski, C.; Trimble, R. B. Anal. Biochem. 2000, 278, 111-122.

26. Shaka, A. J.; Barker, P. B.; Freeman, R. J. Magn. Reson. 1985, 64, 547-552.

27. Gattiker, A.; Rischatsch, R.; Demougin, P.; Voegeli, S.; Dietrich, F. S.; Philippsen, P.; Primig, M. BMC Genomics 2007, 8, 9.

28. Cantarel, B. L.; Coutinho, P. M.; Rancurel, C.; Bernard, T.; Lombard, V.; Henrissat, B. Nucleic Acids Res. 2009, 37, D233-D238.

29. Vliegenthart, J. F. G.; Dorland, L.; van Halbeek, H. Adv. Carbohydr. Chem. Biochem. 1983, 41, 209-374.

30. Jongen, S. P.; Gerwig, G. J.; Leeflang, B. R.; Koles, K.; Mannesse, M. L.; van Berkel, P. H.; Pieper, F. R.; Kroos, M. A.; Reuser, A. J.; Zhou, Q.; Jin, X.; Zhang, K.; Edmunds, T.; Kamerling, J. P. Glycobiology 2007, 17, 600-619.

31. Blanchard, V.; Gadkari, R. A.; Gerwig, G. J.; Leeflang, B. R.; Dighe, R. R.; Kamerling, J. P. Glycoconjugate J. 2007, 24, 33-47.

32. Trimble, R. B.; Atkinson, P. H.; Tschopp, J. F.; Townsend, R. R.; Maley, F. J. Biol. Chem. 1991, 266, 22807-22817.

33. Trimble, R. B.; Atkinson, P. H. J. Biol. Chem. 1986, 261, 9815-9824.

34. Hernandez, L. M.; Ballou, L.; Alvarado, E.; Tsai, P.; Ballou, C. E. J. Biol. Chem. 1989, 264, 13648-13659.

35. Manzi, A. E.; Norgard-Sumnicht, K.; Argade, S.; Marth, J. D.; van Halbeek, H.; Varki, A. Glycobiology 2000, 10, 669-689.

36. Park, J. N.; Lee, D. J.; Kwon, O.; Oh, D. B.; Bahn, Y. S.; Kang, H. A. J. Biol. Chem. 2012, 287, 19501-19515.

37. Montesino, R.; Nimtz, M.; Quintero, O.; Garcia, R.; Falcón, V.; Cremata, J. A. Glycobiology 1999, 9, 1037-1043.

38. Kim, M. W.; Rhee, S. K.; Kim, J.; Shimma, Y.; Chiba, Y.; Jigami, Y.; Kang, H. A. Glycobiology 2004, 14, 243-251.

39. Song, Y.; Choi, M. H.; Park, J. N.; Kim, M. W.; Kim, E. J.; Kang, H. A.; Kim, J. Y. Appl. Environ. Microbiol. 2007, 73, 4446-4454.

40. Stals, I.; Sandra, K.; Geysens, S.; Contreras, R.; Van Beeumen, J.; Claeyssens, M. Glycobiology 2004, 14, 713-724.

41. Kainz, E.; Gallmetzer, A.; Hatzl, C.; Nett, J. H.; Li, H.; Schinko, T.; Pachlinger, R.; Berger, H.; Reyes-Dominguez, Y.; Bernreiter, A.; Gerngross, T.; Wildt, S.; Strauss, J. Appl. Environ. Microbiol. 2008, 74, 1076-1086.

42. Wallis, G. L. F.; Easton, R. L.; Jolly, K.; Hemming, F. W.; Peberdy, J. F. Eur. J. Biochem. 2001, 268, 4134-4143.

43. Ballou, L.; Hernandez, L. M.; Alvarado, E.; Ballou, C. E. Proc. Natl. Acad. Sci. 1990, 87, 3368-3372.

44. Choi, B. K.; Bobrowicz, P.; Davidson, R. C.; Hamilton, S. R.; Kung, D. H.; Li, H.; Miele, R. G.; Nett, J. H.; Wildt, S.; Gerngross, T. U. Proc. Natl. Acad. Sci. 2003, 100, 5022-5027.

45. Romero, P. A.; Lussier, M.; Véronneau, S.; Sdicu, A. M.; Herscovics, A.; Bussey, H. Glycobiology 1999, 9, 1045-1051.

46. Maras, M.; De Bruyn, A.; Schraml, J.; Herdewijn, P.; Claeyssens, M.; Fiers, W.; Contreras, R. Eur. J. Biochem. 1997, 245, 617-625.

47. Odani, T.; Shimma, Y.; Wang, X. H.; Jigami, Y. FEBS Lett. 1997, 420, 186-190.

48. Jigami, Y.; Odani, T. Biochim. Biophys. Acta 1999, 1426, 335-345.

49. Stals, I.; Samyn, B.; Sergeant, K.; White, T.; Hoorelbeke, K.; Coorevits, A.; Devreese, B.; Claeyssens, M.; Piens, K. FEMS Microbiol. Lett. 2010, 303, 9-17.

50. Fujita, K.; Kobayashi, K.; Iwamatsu, A.; Takeuchi, M.; Kumagai, H.; Yamamoto, K. Arch. Biochem. Biophys. 2004, 432, 41-49. 